\title{
Comparison of spray dose measured on leaf surfaces with spray coverage estimated from Kromekote ${ }^{\circledR}$ paper
}

\author{
R.L. Roten ${ }^{1}$, R.J. Connell ${ }^{1}$, A.J. Hewitt ${ }^{2}$ and S.J.R. Woodward ${ }^{1}$ \\ ${ }^{1}$ Lincoln Agritech Ltd., PO Box 69133, Lincoln, Christchurch 7640, New Zealand \\ ${ }^{2}$ The University of Queensland, Gatton QLD 4343, Australia \\ Corresponding author: rory.roten@lincolnagritech.co.nz
}

\begin{abstract}
The control of tomato potato psyllid largely depends on effective application of pesticides. This paper presents an experiment to measure deposition using leaf washing of spray containing water and rhodamine dye on a potato canopy. The treatments included conventional boom, canopy submerged DropSpray ${ }^{\circledR}$ combination, electrostatic spraying system (both engaged and disengaged) and air-assisted rotary atomizer. During the same experiment the quality of coverage was measured using Kromekote ${ }^{\circledR}$ paper. Comparison of both sampling methods illustrated a rapid decrease of deposited material as it descended through the canopy. The leaf washing indicated more deposition within the canopy with the DropSpray ${ }^{\circledR}$ unit and a sampler difference when the electrostatics either were engaged or disengaged. It was concluded that Kromekote ${ }^{\circledR}$ paper cannot provide direct comparative analysis of spray dose on real leaves and its position affected the results. Finally, novel spray technologies gave better deposition to the undersides of leaves.
\end{abstract}

Keywords tomato-potato psyllid, coverage, pesticide dose, sprayer technology.

\section{INTRODUCTION}

Tomato potato psyllid control and prevention has been reported to cost approximately $\$ 28$ million per annum (Kale 2011), which is largely due to the frequent applications of pesticide. Previous work (Roten et al. 2013) evaluated six spray delivery systems using Kromekote ${ }^{\circledR}$ (K-cards) to collect qualitative data on spray coverage at designated heights adjacent to leaves to further assess deposition throughout the potato canopy. The aim was to examine the three-dimensional deposition on both sides of the K-card in the top, middle and bottom canopy strata. The work concluded that similar coverage is achievable with application volumes ranging from 167 to 260 litres/ha with novel spray technologies compared with the standard application volumes tested with a conventional boom with flat-fan nozzles and a grower-standard air-assisted boom, spraying 300 and 400 litres/ha, respectively.

The experiment undertaken for the previous work also collected quantitative data by using the leaf washing technique to measure the amount of active ingredient (AI) deposited by the spray on the potato canopy leaves at the same designated heights. However, debate remains concerning whether droplets per unit area measurements are an effective quantitative measure of coverage, as this measurement does not directly express the amount of active ingredient (AI) deposited. Previous studies have attempted to compare artificial collectors and deposition on natural canopies. For example, Forster et al. (2014) 
looked at the effects of collection efficiency, specifically bouncing of droplets, and showed that the artificial collector, while having the ability to collect all the spray that reaches its surface, will not have the same retention or spreading properties as natural foliage. In addition, the relative advantages of natural and artificial collectors have been discussed by Koch \& Knewitz (2006). To analyse AI deposition directly, timeconsuming and often expensive methodologies are required, including chromatography and various fluorometric tactics (Waite 1977; Nordbo 1992; Hoffmann et al. 2007; Fritz et al. 2009). Additional concerns exist regarding collector types to assess spray deposition because artificial collectors have their own collection efficiency, texture and rigidity, which will likely never match the physical characteristics of a natural leaf surface. Therefore, the objectives of this paper were to compare the percent AI deposited on a natural, leaf collector against the percent area covered on $\mathrm{K}$-card paper, as well to assess any differences in deposition between varying sprayer technologies using the leaf washing dataset.

\section{MATERIALS AND METHODS}

A full description of the experimental methods for the K-card study can be found in Roten et al. (2013). In short, K-cards were horizontally placed at the top, middle and lower canopy; each card was marked to specify the upper and lower sides. For consistency, a single, $2 \% \mathrm{v} / \mathrm{v}$ mix of rhodamine WT (Abbey Color, Philadelphia, Pennsylvania, USA) was used for all treatments. After spraying, the cards were stored and later computationally analysed using a high resolution scanner where $4 \mathrm{~cm}^{2}$ was randomly scanned, images saved and converted to a black and white image and coverage determined using Matlab (7.2.0.323) software. During this experiment, simultaneous leaf washing and physical capture of the rinsate were also conducted for later comparison.

During the trial 600 samples were taken: four plants in each treatment, with measurements being made on each plant at three heights (lower, middle and upper canopy), five leaves per height and two leaf sides (upper and lower), with the same leaf being used for the leaf sides measurements. The five treatments (Table 1) selected for analysis were: (1) a conventional fournozzle boom paired with fine twin-tip nozzles (type TJ60-110-04, Teejet Spraying Systems, Wheaton, Illinois, USA) at an application volume of 300 litres/ha, (2) a combination application where $25 \%$ of each swath was sprayed with a conventional boom with Teejet XR 110-04 nozzles and $75 \%$ from an engineered, up-angled drop-nozzle (DropSpray ${ }^{\circledR}$, Micron Sprayers Ltd., Bromyard, UK) system with WRW-4 nozzles (Delavan, Eau Claire, Wisconsin, USA) applying 260 litres/ha, (3) a pneumatic atomiser in combination with induced electrostatic charge spray system (Electrostatic Spraying Systems (ESS) MaxCharge ${ }^{\mathrm{TM}}$ nozzles, ESS, Watkinsville, Georgia, USA) at 167 litres/ha with charge disengaged (ESS/off), (4) the same ESS MaxCharge ${ }^{\mathrm{TM}}$ system with charge engaged (ESS/on) and (5) an air-assisted rotary cage style atomiser (Proptec ${ }^{\mathrm{TM}}$ PT100, Ledebuhr Industries, Lansing, Michigan, USA) delivering 200 litres/ha.

Driving speeds ranged between 4.7 and $6.8 \mathrm{~km} / \mathrm{h}$, based on manufacturer recommendations or local grower standards for the given technology. Once the sprayer was calibrated, a spray solution of $0.2 \% \mathrm{v} / \mathrm{v}$ Rhodamine WT (Abbey Color, Philadelphia, Pennsylvania, USA) fluorescent tracing dye and $1 \% \mathrm{v} / \mathrm{v}$ Actiwett ${ }^{\mathrm{TM}}$ non-ionic surfactant (Nufarm, Middleton, NZ) was added as a standard spreader/sticker adjuvant. To reduce unnecessary variability, a single, large solution of dye was mixed so that all applications sprayed exactly the same concentration, regardless of application volume.

Leaf washing methods used ethanol to assist in the extraction of the dye from the leaf surface and stabilize rhodamine from breaking down (T. Wolf, Agriculture Agri-Food Canada, personal communication). Quantitative dose data were acquired by manually rinsing individual leaf sides with $20 \mathrm{ml}$ of a 90:10 water:ethanol solution with a syringe. Washing the leaves in this manner was time consuming and risked human error. For the first treatment only, all leaves were harvested at 
Table 1 Detailed treatment information.

\begin{tabular}{llccc}
\hline Treatment & $\begin{array}{l}\text { Droplet size } \\
\text { classification }\end{array}$ & $\begin{array}{c}\text { Application volume } \\
(\text { litres/ha })\end{array}$ & $\begin{array}{c}\text { Driving speed } \\
(\mathrm{km} / \mathrm{h})\end{array}$ & $\begin{array}{c}\text { Air assistance } \\
(\mathrm{m} / \mathrm{sec})\end{array}$ \\
\hline Conventional Boom & Medium & 300 & 6.8 & $\mathrm{na}$ \\
DropSpray ${ }^{\circledR}$ & Up:fine, Drop:coarse & 260 & 6.8 & $\mathrm{na}$ \\
ESS/off & Very fine & 167 & 4.7 & 25 \\
ESS/on & Very fine & 167 & 4.7 & 25 \\
Proptec $^{\mathrm{TM}}$ & Fine & 200 & 6.8 & 20 \\
\hline
\end{tabular}

the same time and it was quickly discovered that this was unwise due to the fast wilting and loss of the needed rigidity. Therefore subsequent plots were harvested one leaf at a time. After washing was complete, the rinsate was stored in resealable plastic bags and leaves were individually stored in paper bags. All samples were placed in dark, cold storage until laboratory analysis. Fluoremetric analysis was run in unison of treatments so that samples were in storage for no longer than $3 \mathrm{~h}$ to avoid any potential degradation. Samples were analysed in a fluorometer calibrated to provide a linear RFU (relative fluorescence unit) value with a RWT/PE module with $550 \mathrm{~nm}$ excitation wavelength (Turner Trilogy ${ }^{\circledR}$, Turner Designs, Sunnyvale, CA, USA). A standard curve was then used to convert the RFU data to $\mu \mathrm{l} /$ litre. For this, a stock solution of $2 \% \mathrm{v} / \mathrm{v}$ rhodamine WT was made using the 90:10 water:ethanol extract mix and processed using increasing sample concentrations until quenching was observed; linearity was observed up to 100,000 RFUs and samples above this value were diluted and reprocessed accordingly.

Leaf area was calculated using a LI-COR LI-3100 (LI-COR Inc., Lincoln, Nebraska, USA) and matched with the leaf wash data. These data were then converted to percent applied by using the ppm per $20 \mathrm{ml}$ sample (the extraction volume), divided by the leaf area $\left(\mathrm{g} / \mathrm{cm}^{2}\right)$, then converted to litres/ha and normalized per application rate. Percent coverage data from the K-cards were also normalised against the conventional sprayer and all deposition data were then plotted using Sigmaplot (version 13.0) for side by side comparison. For comparison of the two sampling methods, leaf sides were combined. Percent application data were also subjected to Tukey's HSD $(\mathrm{P}<0.05)$ within $\mathrm{R}($ version 3.2.0) to examine deposition data between treatments, canopy heights and leaf sides.

\section{RESULTS AND DISCUSSION}

The relationships between the percent coverage on the K-cards and the percent AI deposited on actual leaves are illustrated in Figure 1. Overall deposition rapidly decreased as the particles travelled down through the canopy, both in terms of coverage and AI deposited. However, the $\mathrm{K}$-cards' percent coverage data did not indicate how much chemical was reaching the target. For example, as the percent coverage data neared and exceeded $100 \%$ (for normalised data), the percent AI deposited ranged between 75 and $415 \%$. It can also be observed that when the percent coverage data were lower, such as in the DropSpray ${ }^{\circledR}$ treatment, there was less difference between the two measures.

Differences in deposition between samplertypes can also be observed by differing technologies, most notably with electrostatics (Figures 1d \& 1e). When the electrostatic charge is disengaged, there is a modest increase to the $\mathrm{K}$-card coverage readings, which is contrary to the observed decrease in deposition on the actual leaves. Conversely, for the ESS/on treatment, there is a decrease of percent coverage on the $\mathrm{K}$-cards, presumably because the dye was instead attracted to the plant matter by the electrical charge (Marchant \& Green 1982). However, in regards to electrostatic technologies, the grounding of the live plants is a distinguishing 
characteristic and using one of these systems in a disengaged manner would be unrealistic. When using electrostatic sprayers, the correct application must be prescribed depending on what chemical(s) is being sprayed, what pests or weeds are targeted and what the targets' characteristics are (Hislop et al. 1983). For instance, if the AI is systemic the coverage is likely a nonissue; or if the weed species are shorter than the crop, electrostatics will prohibit the herbicide from reaching the actual target.

The deposition of dye throughout the canopy was consistent with the findings of Roten et al. (2013) where similar patterns coverage were observed between all sprayers (Table 2). The previous K-card work (Roten et al. 2013) observed less coverage than expected with the DropSpray ${ }^{\circledR}$ system. The two most notable differences between the two datasets are that (1) the conventional boom applied 389\% AI to the upper most canopy and leaf side, which is statistically different $(\mathrm{P}<0.05)$ from all other treatments and (2) the Proptec ${ }^{\mathrm{TM}}$ atomiser deposited greater amounts of AI on the lower leaf side of the upper canopy than would have been expected from the $7.6 \%$ coverage indicated in the previous study. However, dose results on the leaf underside of the lower canopy (Table 2) suggest greater deposition with the drop-spray application. It is believed that the difference between the coverage and dose results is due to the positioning of the droplegs, which sprayed $75 \%$ of the spray volume in an upwards fashion within the canopy whereas the K-card stands were within the rows, as close to the plants as possible but were not the direct spray target. Both datasets saw better uniformity than expected among canopy strata regardless of application on the upper leaf sides. Although significantly more deposition was observed from the conventional sprayer on the upper leaf side at the upper canopy, all other technologies performed better on the under leaf side at the lower and middle canopy heights.

It would be preferable to test the coverage and dose response on identical collectors. However, this is not always feasible in field study situations. For example, with the potato study it was not practical to use the actual leaves to discern the percent coverage because harvested biomass quickly lost rigidity through wilt. Conversely, it is not appropriate to obtain percent $\mathrm{AI}$ from the paper surface because it does not share important physical characteristics of real leaves, which

Table 2 Spray deposit (\% AI) to the upper and under leaf-side from five spray treatments measured at three canopy heights. For each leaf-side dataset, means within column followed by the same letter and Greek letters within rows are not statistically different based upon Tukey's HSD $(\mathrm{P}<0.05)$.

\begin{tabular}{|c|c|c|c|c|c|c|}
\hline \multirow{3}{*}{$\frac{\text { Treatment }}{\text { Upper leaf-side }}$} & \multicolumn{6}{|c|}{ Canopy Height } \\
\hline & \multicolumn{2}{|c|}{ Lower } & \multicolumn{2}{|c|}{ Middle } & \multicolumn{2}{|c|}{ Upper } \\
\hline & 27.5 & a $\alpha$ & 48.4 & a $\alpha$ & 389.3 & a $\beta$ \\
\hline DropSpray ${ }^{\circledR}$ & 34.9 & a $\alpha$ & 54.2 & a $\alpha$ & 196.1 & $\mathrm{bc} \alpha$ \\
\hline ESS/off & 21.5 & a $\alpha$ & 58.5 & a $\alpha$ & 101.1 & $d \beta$ \\
\hline ESS/on & 57.6 & a $\alpha$ & 59.4 & a $\alpha$ & 225 & $\operatorname{bcd} \beta$ \\
\hline Proptec $^{\mathrm{TM}}$ & 56.7 & a $\alpha$ & 61.8 & a $\alpha$ & 232.7 & $\mathrm{~b} \beta$ \\
\hline \multicolumn{7}{|l|}{ Under leaf-side } \\
\hline Conventional boom & 2.2 & $c \alpha$ & 1.8 & $c \alpha$ & 26.0 & $\mathrm{~b} \beta$ \\
\hline DropSpray ${ }^{\circledR}$ & 29.4 & a $\alpha$ & 7.5 & $\operatorname{abc} \alpha$ & 19.0 & $\mathrm{~b} \alpha$ \\
\hline ESS/off & 2.9 & $c \alpha$ & 4.9 & bc $\alpha \beta$ & 16.3 & $\mathrm{~b} \beta$ \\
\hline ESS/on & 6.9 & bc $\alpha$ & 9.4 & $\mathrm{abc} \alpha$ & 26.6 & $\mathrm{~b} \beta$ \\
\hline Proptec ${ }^{\mathrm{TM}}$ & 12.9 & $\operatorname{abc} \alpha$ & 13.1 & a $\alpha$ & 162.6 & a $\beta$ \\
\hline
\end{tabular}



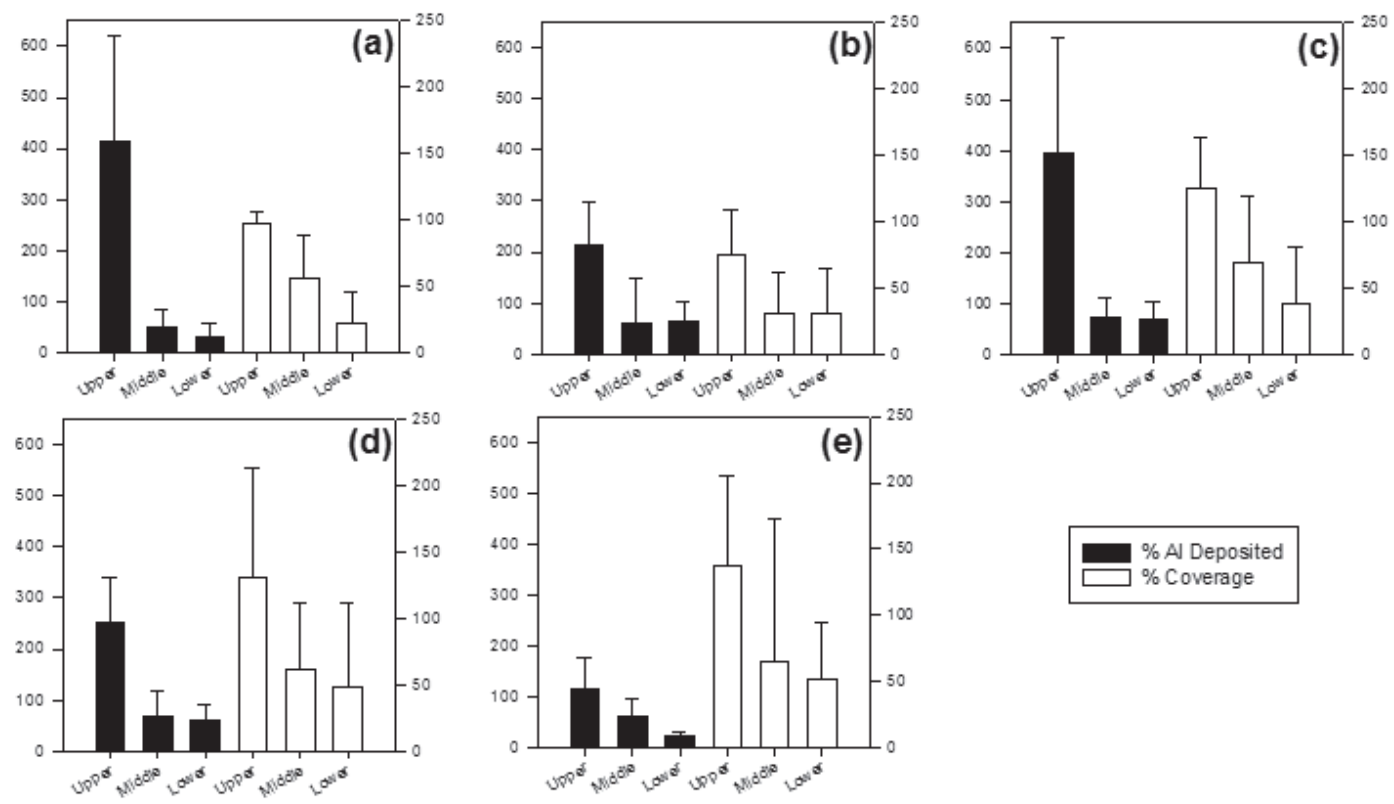

Figure 1 Leaf deposition obtained through leaf washing (\% AI deposited) and dye coverage on K-cards (\% Coverage) for spray application with (a) a conventional four-nozzle boom, (b) a set-up using DropSpray ${ }^{\circledR}$ nozzles, (c) an air-assisted Proptec ${ }^{\mathrm{TM}}$ set-up, (d) a set-up using Electrostatic Spraying Systems (ESS) MaxCharge ${ }^{\mathrm{TM}}$ system with electrostatic charge turned on and (e) the same ESS set-up with electrostatic charge turned off, at upper, middle and lower canopy heights.

affect droplet retention, spread, adsorption and absorption, for example. Furthermore, in the present study, the droplet size classifications in Table 1 range between very fine and course, implying droplet volume median diameters between approximately 60 and $700 \mu \mathrm{m}$ (Anon. 2009), which does pose an unavoidable variance in this facet of research as no single collector is efficient for all droplet size classes.

In conclusion, it is apparent that Kromekote ${ }^{\circledR}$ paper cannot provide direct comparative analysis of pesticidal dose on to real leaves. Nonetheless, the use of such sampling methodologies has been useful in the assessment of application equipment and environmental exposure. The work presented here supports the original findings that the use of one or more novel spray technology provided better deposition to leaf undersides than the conventional boom with 13 to $44 \%$ less spray volume.

\section{ACKNOWLEDGMENTS}

This research was funded through a grant from The Ministry for Business, Innovation and Employment, Contract LVLX0901 - "Protecting NZ's Environment from Pesticide Exposure". The authors would also like to thank everyone who helped with this study. We are particularly grateful to Mr Howe Young for allowing us to use his crop for this research, Paul Munro of Peracto Ltd., who hosted the field study and was integral in site selection and extensive assistance throughout the research, Stephen Ogden of Potatoes NZ for site assistance and insight, Electrostatic Spraying Systems and Pacific Grower Services for use and assistance with the ESS machinery, Micron Group and Ledebuhr Industries for providing insight and equipment for this study, Roger Cook of Lincoln Agritech for assistance in assembling and devising the wide range of machinery under very short timelines. 


\section{REFERENCES}

Anon. 2009. Spray Nozzle Classification by Droplet Spectra. American Society of Agricultural and Biological Engineering: 1.

Forster WA, Gaskin RE, Strand TM, Manktelow DWL, van Leeuwen RM 2014. Effect of target wettability on spray droplet adhesion, retention, spreading and coverage: artificial collectors versus plant surfaces. New Zealand Plant Protection 67: 284-291.

Fritz B, Parker C, López Jr J, Hoffmann W, Schleider P 2009. Deposition and droplet sizing characterization of a laboratory spray table. Applied Engineering in Agriculture 25: 175-180.

Hislop EC, Cooke BK, Harman JMP 1983. Deposition and biological efficacy of a fungicide applied in charged and uncharged sprays in cereal crops. Crop Protection 2: 305-316.

Hoffmann W, Walker T, Martin D, Barber J, Gwinn T, Smith V, Szumlas D, Lan Y, Fritz B 2007. Characterization of truck-mounted atomization equipment typially used in vector control. Journal of the American Mosquito Control Association 23: 321-329.

Kale A 2011. Report on the economic and business impacts of potato psyllid on the potato industry. Prepared for Potatoes New Zealand. http://www.potatoesnz.co.nz/ users/Image/Downloads/PDFs/Potato $\% 20$ Economic\%20survey\%20Report\%20Jun\%20 2011_V2.pdf (accessed 14 February 2013).
Koch H, Knewitz H 2006. Methodology and sampling technique of spray deposit and distribution measurement in orchards. Nachrichtenblatt des Deutschen Pflanzenschutzdienstes 58: 6-9.

Marchant JA, Green R 1982. An electrostatic charging system for hydraulic spray nozzles. Journal of Agricultural Engineering Research 27: 309-319.

Nordbo E 1992. Effects of nozzle size, travel speed and air assistance on deposition on artificial vertical and horizontal targets in laboratory experiments. Crop Protection 11: 272-278.

Roten RL, Hewitt AJ, Ledebuhr M, Thistle H, Connell RJ, Wolf TM, Sankar S, Woodward SJR 2013. Evaluation of spray deposition in potatoes using various spray delivery systems. New Zealand Plant Protection 66: 317-323.

Waite RA 1977. Spread factors of pesticidal spray formulations on Kromekote cards. Department of Agriculture, Forest Service, Pacific Northwest Forest and Range Experiment Station, Portland, Oregon, USA. Pp. 1-8. 